Original Research

\title{
Descriptive Strength and Range of Motion in Youth Baseball Players
}

\author{
Ross M Nakaji, PT, MSPT, OCS, SCS, ATC, CSCS $^{1}$ a , Todd S Ellenbecker, PT, DPT, MS, SCS, OCS, CSCS ${ }^{2}$ Kevin M \\ McClenahan, PT, DPT, OCS ${ }^{1}$, Lianna M Roberts, PT, DPT, OCS ${ }^{1}$, Chase Perez, PT, DPT, SCS, CSCS ${ }^{1}$, Scott B Dickenson, \\ PT, DPT, ATC ${ }^{3}$ \\ ${ }^{1}$ Los Gatos Orthopedic Sports Therapy, Inc., ${ }^{2}$ Rehab Plus Sports Therapy Scottsdale, ${ }^{3}$ Excel Physical Therapy \\ Keywords: shoulder, rotator cuff strength, range of motion, baseball \\ https://doi.org/10.26603/001c.18815
}

\section{International Journal of Sports Physical Therapy}

Vol. 16, Issue 1, 2021

\section{Background}

There are limited studies reporting descriptive strength and range of motion in youth baseball players 12 years of age or younger.

\section{Purpose}

To establish normative data for external (ER) and internal (IR) rotation range of motion (ROM), total arc range of motion (TROM), and isometric rotator cuff strength in youth baseball players, and to compare between the dominant throwing arm (D) to the non-dominant arm (ND).

\section{Study Design}

Cross-sectional

\section{Methods}

Patient population included 50 (5 to 12 -year-old) uninjured, healthy athletes. ROM measurements were performed preseason using a goniometer for IR and ER in the supine position with the shoulder in 90 degrees of abduction (abd) with scapular stabilization. Isometric strength measurements for IR and ER were collected in both neutral and 90 degrees (deg) of abduction with the use of a hand-held dynamometer and recorded in pounds (lbs) utilizing a "make" test. Descriptive statistics were obtained for all measures.

\section{Results}

All data were analyzed as a single group (average age: 9.02). No significant difference in average total arc of PROM (ER+IR=Total Arc) on the D side compared to the ND side $(136.7 \pm 12.7 \mathrm{deg}$ vs. $134.3 \pm 12.3 \mathrm{deg})$. There were statistically significant differences between ER ROM (102.2 $\pm 7.7 \mathrm{deg}$ vs. $96.8 \pm 7.4 \mathrm{deg})$ and IR ROM $(34.4 \pm 9.0 \mathrm{deg}$ vs. $37.5 \pm$ $9.5 \mathrm{deg}$ ) between D versus ND arms ( $\mathrm{p}=.000, .006$ respectively). Mean ER strength in neutral $(13.6 \pm 3.4$ and $12.8 \pm 3.6 \mathrm{lbs})$ and $90 \mathrm{deg}$ abduction $(12.3 \pm 3.4$ and $12.5 \pm 4.3 \mathrm{lbs})$ did were not significantly different between $\mathrm{D}$ and ND arms, respectively. Mean IR strength in neutral $(18.0 \pm 6.0$ and $15.7 \pm 4.7 \mathrm{lbs})$ and $90 \mathrm{deg}$ abd $(16.4 \pm 5.6$ and $15.0 \pm 5.7$ $\mathrm{lbs})$ was significantly greater in the $\mathrm{D}$ arm vs ND arm, respectively $(\mathrm{p}=.000, .001)$.

\section{Conclusion}

These data can provide descriptive information for clinicians who treat very young

\footnotetext{
a Corresponding author:

Ross Nakaji,

Los Gatos Orthopedic Sports Therapy, Inc.

16615 Lark Ave. Suite 101

Los Gatos, CA 95032

Phone: (408) 358-1460

E-mail: rnakaji@lgost.com
} 
baseball players. These data show sport specific adaptations occur at very young ages (5-12) and are similar to prior reports on adolescent, high school and professional baseball players regarding upper extremity ROM and rotator cuff strength.

\section{Level of Evidence}

\section{INTRODUCTION}

Glenohumeral joint range of motion (ROM) adaptations in IR and TROM have been identified in elite baseball and tennis players primarily in the direction of internal rotation (IR) and total rotational motion (TROM= External + Internal Rotation ROM). ${ }^{1-5}$ These changes or adaptations in glenohumeral joint ROM have also been reported in other unilaterally dominant upper extremity sport athletes such as tennis, volleyball players and swimmers as well, but have been studied primarily in baseball pitchers. 3,5,6

It is well known that the overhead throwing athlete develops changes in shoulder ROM, specifically a loss of glenohumeral IR. ${ }^{7,8}$ This loss of IR ROM with an accommpanying increase in external rotation (ER) ROM can place the overhead throwing athlete at risk of injury. ${ }^{8}$ Previous authors have specified that glenohumeral internal rotation deficit (GIRD) in itself is not necessarily considered deleterious to throwing motion or risk of injury. Rather a change in the total arc of motion between dominant (D) and nondominant (ND) arms is when GIRD can be pathologic. 3,9-12

Total arc of motion is defined as the sum of ER and IR ROM (Figure 1) and has been reported to be a total of 160-180 degrees. ${ }^{12}$ Overhead throwing athletes notoriously have a shift in measured ER and IR ROM, with the D throwing arm presenting with limited IR and excessively increased ER in order to provide the necessary torque required to pitch. ${ }^{13-15}$ The ability to throw at high velocities requires adaptations to occur within the athlete's shoulder complex that are not typically seen in the ND side of throwers, or in the shoulders of non - throwing individuals. ${ }^{16}$ For example, a baseball pitcher with a D arm total arc ROM (105 degrees of $\mathrm{ER}+55$ degrees of IR $=160 \mathrm{TROM}$ ) versus ND arm (90 degrees of $\mathrm{ER}+70$ degrees of IR $=160$ degrees of TROM) would be considered to have an anatomic GIRD / adaptation and this athlete would not be considered at risk for further shoulder injury due to symmetrical TROM.

Pathologic GIRD is defined as when there is a loss of glenohumeral IR greater than $18^{\circ}-20^{\circ}$ with a corresponding loss of total arc of motion greater than $5^{\circ}$ when compared bilaterally. ${ }^{9-13}$ For example, a baseball pitcher with a D arm total arc $(110+50=160)$ and ND arm total arc $(80+$ $70=150$ ) would be considered pathologic and at risk for future shoulder or elbow injury. $5,13,16$

In addition to changes in available ROM, muscle imbalances may occur of the rotator cuff and scapular stabilizers contributing to further asymmetry which relates to control of the throwing motion. ${ }^{13}$ Increased dominance of internal rotator muscles and impaired recruitment of external rotators, especially in eccentric control, may put throwing athletes at risk for injury. ${ }^{17}$ The late cocking phase and follow through phases are especially susceptible to excessive tensile load across shoulder structures. ${ }^{14,18-20}$ Dynamic con-
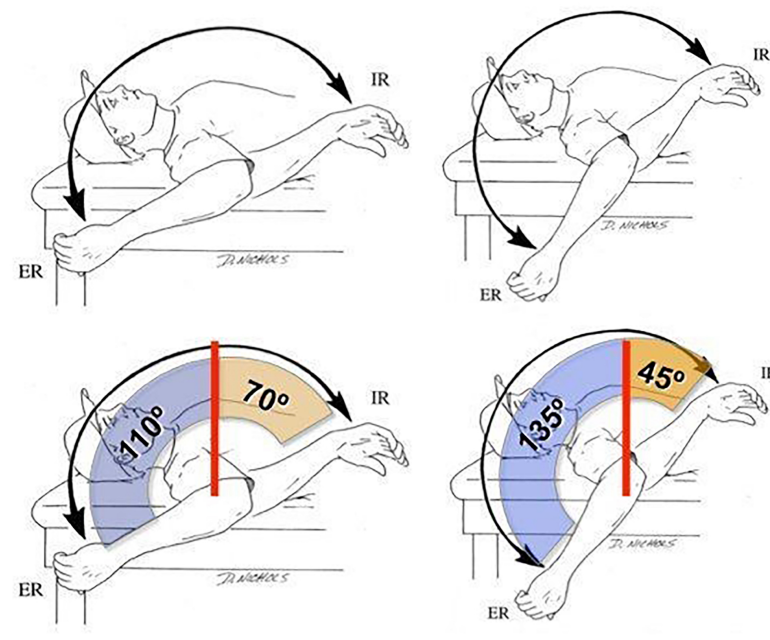

Figure 1: Total Arc of Motion (TROM)

trol and proprioceptive input are critical in maintaining scapulothoracic and rotator cuff stability during the overhead throwing motion. ${ }^{12,14,21-23}$

Muscle timing and recruitment are key components in maintaining proximal stability for distal mobility during arm motion. Researchers have shown decreased output of the scapular stabilizers (such as the serratus anterior) to occur with dominance of internal rotators (such as the pectoralis major and minor) along with impaired strength of the posterior rotator cuff needed for control and deceleration of the arm in throwing. ${ }^{20,21}$

Most of the available research has demonstrated normative and descriptive data profiles for shoulder ROM and strength of the adult or older adolescent athlete, whereas minimal research is available for adolescent throwing athletes under the age of 12 . Young athletes are often specializing in a single sport at earlier ages, dedicating their time year round to one sport and one position, ${ }^{22}$ despite the American Academy of Pediatrics recommending a minimum of two months off per year with a minimum of one day off per week to minimize overuse injuries in the adolescent athlete. ${ }^{23}$ Thus, the authors are aware of the fact that these overuse injuries are beginning to occur at younger and younger ages. ${ }^{24-27}$ We are less aware, however, of what age young overhead athletes begin to develop glenohumeral rotation deficits and rotational muscle imbalances. This information would be important to rehabilitation professionals working with young overhead athletes to perhaps reduce the risk for injury. ${ }^{26}$

The purpose of this research was to establish descriptive data by measuring shoulder IR and ER ROM, total arc range of motion (TROM), and isometric strength and determine if differences exist between the D and ND extremity in athletes 12 years of age or younger. Research identifying the 
descriptive profile of total arc range of motion in healthy, uninjured youth baseball players will allow clinicians and scientists to better interpret findings of preventative evaluations and during the examination of youth baseball players. It was hypothesized that youth baseball athletes aged 5-12 years old would show throwing-related adaptations in shoulder strength and ROM in the D versus the ND arm.

\section{METHODS}

Study participants were recruited from a local youth baseball league during opening day festivities prior to the start of the season. Subjects were included if they were between the ages of 5 and 12 and had no current shoulder pain or injury, and no history of shoulder or elbow surgery in either upper extremity. Participants were also excluded if they had any shoulder injury in the prior year that prevented baseball competition or training.

\section{PROCEDURES}

All participants were measured on opening day of the 2012 baseball season. Before data collection, the parent/guardian read and signed the informed consent form approved by the institutional review board of Physiotherapy Associates, Exton, PA. Subjects were assigned a number that represented their involvement in this study. This number was used in lieu of their name to minimize the risk and ability of their identity being disclosed to persons other than the primary investigator. After informed consent was signed demographic information was collected (age, arm dominance). Participants were then instructed to report to either a strength or range of motion testing location for evaluation based on convenience. Subjects were measured bilaterally in a random order to prevent any effects of bias for both ROM and strength measures.

For ROM measurement, participants were placed supine on a portable treatment table without a pillow under their head, with the arm in 90 degrees of shoulder abduction and 90 degrees of elbow flexion. Subjects were asked to retract their scapulae bilaterally and then lie in a relaxed position for the duration of the testing. The superior border of the scapula was stabilized in a relaxed position by one hand of the examiner using a thumb on the corocoid process (Fig$\underline{\text { ure 3) }}$ to prevent/minimize scapular substitution. ${ }^{5,28}$ From this position the examiner passively moved the subject's extremity into external rotation until first resistance was encountered (Figure 2). There was no overpressure applied to the extremity at any time. Gravity was used as a constant force to maintain the end-point position similar to the method used by the authors during measurement of glenohumeral joint internal rotation. ${ }^{1-3,6}$ From neutral rotation the examiner then moved the extremity into internal rotation until first resistance was encountered (Figure 3) using the exact procedure employed for external rotation measurement. A standard method was used with the same therapist collecting all of the ROM and strength measurements. An analog goniometer was then placed along the axial midline of the humerus with one arm vertical representing 0 degrees and the other arm of the goniometer parallel to the lateral border of the ulna. One trial of measurement was

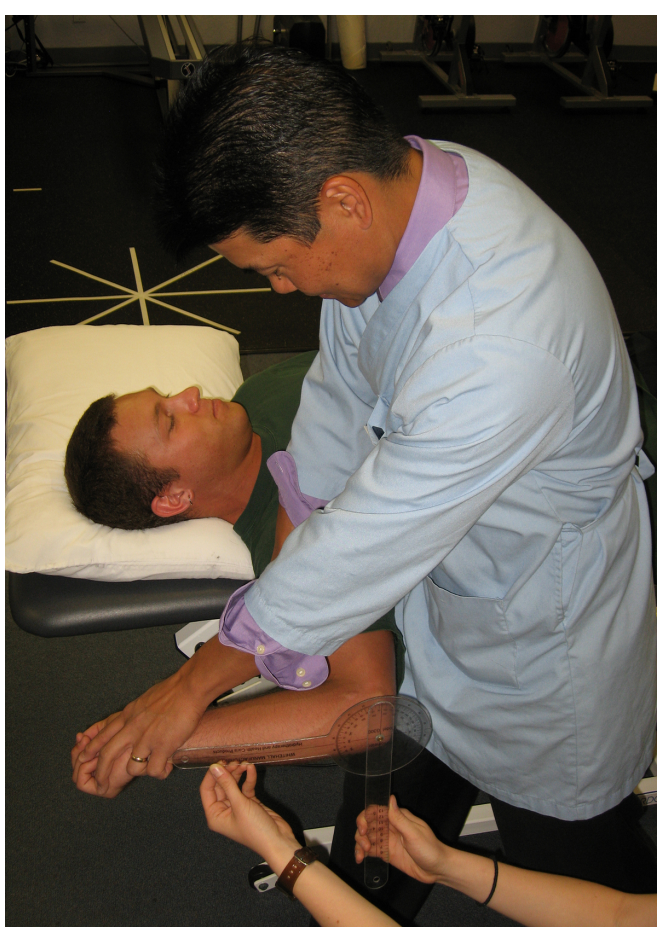

Figure 2: Measurement for external rotation range of motion.

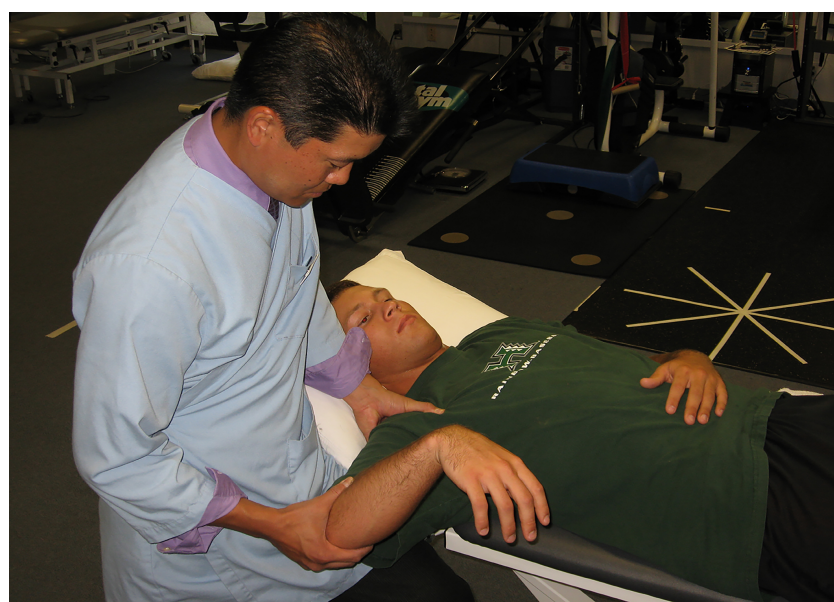

Figure 3: Measurement for internal rotation range of motion.

utilized to represent the subjects' ER and IR ROM for this investigation. Bilateral measurement was performed using identical procedures.

Strength measurements were obtained with the use of a hand held dynamometer (Microfet 2, Hoggan Health Industries, Salt Lake City, UT-Figure 4) and recorded in pounds utilizing a "make" test. ${ }^{29,30}$ The strength tests were performed with the subjects in a standing position with a 3 " $1 / 2$ foam roll under the subjects' axilla to provide sufficient spacing between arm and body. ${ }^{29,30} \mathrm{D}$ and ND sides were randomly chosen and tested using a coin toss to determine which side was tested first. Internal and external rotation strength were tested in this position in neutral shoulder ro- 
Table 1: Descriptive Demographics - Youth Baseball Players (total $\mathbf{n = 5 0}$, all were male)

\begin{tabular}{ll}
\hline Age & N \\
\hline 5 & 2 \\
6 & 1 \\
7 & 6 \\
8 & 9 \\
9 & 9 \\
10 & 15 \\
11 & 7 \\
12 & 7 \\
\hline Arm Dominance & 7 \\
\hline Right & 1 \\
Left & $\mathrm{N}$ \\
\hline
\end{tabular}

Table 2: Shoulder Internal (IR), External (ER), and Total Rotation Range of Motion, mean \pm SD, reported in degrees.

\begin{tabular}{lllll}
\hline Parameter & Dominant Arm & Non-Dominant Arm & t & p-value \\
\hline ER ROM @ 90 AB & $102.2 \pm 7.7$ & $96.8 \pm 7.4$ & 4.42 & 0.000 \\
IR ROM @ 90 AB & $34.4 \pm 9.0$ & $37.5 \pm 9.5$ & -2.88 & 0.006 \\
Total Rotation ROM @ 90 & $136.7 \pm 12.7$ & $134.3 \pm 12.3$ & 1.67 & 0.100 \\
\hline AB= abduction & & & &
\end{tabular}

tation by the same examiner. The hand-held dynamometer was positioned proximal to the wrist on the dorsal and volar aspect of the distal forearm for external and internal rotator strength testing, respectively. The process was completed bilaterally and recorded in a Microsoft Excel spreadsheet. In a random fashion, external and internal rotation strength in 90 degrees of abduction was also tested with the shoulder placed in the coronal plane. Testing took place in a standing position with the shoulder in 90 degrees of ER and 90 degrees of abduction bilaterally.

Data were stored on a Microsoft Excel sheet and SPSS was used to calculate descriptive statistics as well as compare differences between extremities using dependent ttests. A Bonneferoni adjustment was applied due to the use of multiple t-tests (7 tests) to establish a level of significance of $(p<.007)$ to minimize the risk of error.

\section{RESULTS}

Fifty youth male baseball players age 5-12 years old, mean age 9.02 years +1.6 were measured in this cross-sectional study. Table 1 presents the available descriptive demographics for the youth baseball study participants.

\section{RANGE OF MOTION}

Table 2 presents the IR, ER, and TROM data from the 50 subjects included in this study. ER ROM was $102.2 \pm 7.7$ degrees for the $\mathrm{D}$ and $96.6 \pm 7.4$ degrees for the ND extremity. IR ROM was $34.4 \pm 9.0$ and $37.5 \pm 9.5$ for the D and ND extremity respectively. In a similar cross-sectional study of healthy baseball players aged 6-18, Hibberd et $\mathrm{al}^{31}$ also found intergroup ROM differences in players aged 6-10, 11-13, 14-16, and 16-18. Mean TROM was $136.7 \pm 12.7$ degrees and 134.3 \pm 12.3 degrees for the $\mathrm{D}$ and ND extremity respectively. There was no significant difference between extremities for TROM. These data produced significantly greater ER $(p<.001)$ and less IR $(p<.006)$ ROM for the D as compared to the ND extremity.

\section{MUSCULAR STRENGTH}

Table 3 displays the internal and external rotation strength data for both the neutral and 90-degree abducted testing positions. Mean strength measurements in neutral were $13.6 \pm 3.4$ and $12.8 \pm 3.6 \mathrm{lbs}$ for ER, and $18.0 \pm 6.0$ and $15.7 \pm$ $4.7 \mathrm{lbs}$ for IR for the D and ND extremity respectively. Mean strength measurements at 90 degrees abduction were $12.3 \pm$ 3.4 and $12.5 \pm 4.3$ pounds for ER, with $16.3 \pm 5.6$ and $15.0 \pm$ 5.7 pounds for IR for the D and ND extremity respectively. 
Table 3: Shoulder Internal (IR) and External (ER) Rotation Strength measured with a Handheld Dynamometer, displayed at mean \pm standard deviation in pounds

\begin{tabular}{|c|c|c|c|c|}
\hline Parameter & Dominant Arm & Non-Dominant Arm & $\mathrm{t}$ & $\mathrm{p}$-value \\
\hline Shoulder ER (Neutral) & $13.6 \pm 3.4$ & $12.89 \pm 3.6$ & 1.50 & 0.136 \\
\hline Shoulder IR (Neutral) & $18.0 \pm 6.0$ & $15.7 \pm 4.7$ & 4.50 & 0.000 \\
\hline Shoulder ER (90 AB) & $12.3 \pm 3.4$ & $12.5 \pm 4.3$ & -.551 & 0.584 \\
\hline Shoulder IR (90) AB) & $16.4 \pm 5.6$ & $15.0 \pm 5.7$ & 3.60 & 0.001 \\
\hline ER/IR Ratio (Neutral) & 0.76 & 0.82 & & \\
\hline ER/IR Ratio (90 AB) & 0.75 & 0.83 & & \\
\hline
\end{tabular}

$\mathrm{AB}=$ abduction; ER/IR Ratio calculated as ER strength / IR strength

No significant differences were found in ER strength in the neutral or 90 degree abducted position between the $\mathrm{D}$ and ND extremity. In contrast, significantly greater $(\mathrm{p}<.001)$ IR strength was found on the $\mathrm{D}$ arm in both neutral and 90 degrees of glenohumeral joint abduction. External rotation/ internal rotation strength ratios (ER/IR ratio) of the D extremity were 0.76 and 0.75 at neutral and 90 degrees of abduction, respectively. ER/IR ratio for the ND extremity was 0.82 and 0.83 at neutral and 90 degrees of abduction, respectively.

\section{DISCUSSION}

Increased glenohumeral external rotation ROM, decreased internal rotation ROM, and maintenance of total rotation of the $\mathrm{D}$ throwing arm compared to ND arm in uninjured baseball players has been consistently documented at the professional, ${ }^{8-10,13,28,32-35}$ collegiate, ${ }^{36,37}$ high school, $31,38,39$ and little league levels. ${ }^{11,31,40,41}$ A consolidated summary of shoulder range of motion in healthy baseball and tennis players from other authors can be found in Table . $^{3-5,11,13,28,31,33,34,37-48}$ In this study, there was no significant difference in TROM in D vs. ND arms but significantly higher ER ROM and lower IR ROM of the D arm $(p=.000, .006$ respectively). The shoulder ROM findings of this study on youth baseball players with a mean age of 9 are consistent with the established pattern of increased ER and decrease IR. While such ROM characteristics are present in younger age groups, as youth baseball players mature there appear to be gradual yearly alterations in shoulder ROM documented using cross-sectional observations of such populations. Meister et $\mathrm{al}^{11}$ found average external, internal, and total rotational ROM to decrease in both D and ND arms as age increased in healthy youth baseball players aged 8-16. For example, at 8 years of age, Meister et $\mathrm{al}^{11}$ found ER to be 152 and $145 \mathrm{deg}$, IR as 39 and $42 \mathrm{deg}$, and TROM as 191 and $187 \mathrm{deg}$ in D and ND respectively, while at 16 years of age ER to be 143 and $137 \mathrm{deg}$, IR as 35.9 and $41.8 \mathrm{deg}$, and TROM as 179 and $178 \mathrm{deg}$ in D and ND arms respectively (Table 4). This study confirms the findings of Meister et al regarding symmetrical total rotational motion quantities despite ER and IR ROM differences between $\mathrm{D}$ and ND arms. With the exception of ER of the D arm, all rotational shoulder measures were significantly lower in

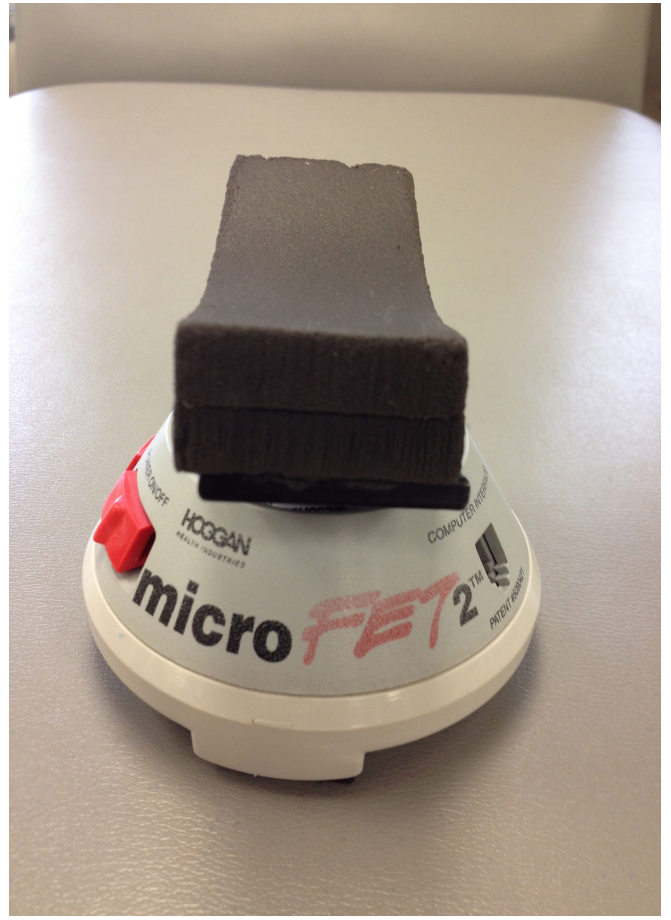

Figure 4: Hand held dynamometer used for strength measures .

the 16-18-year-old group versus the 6-10 -year-old group (Table 4). Additionally, in a study considering the influence of age and skeletal maturity on shoulder ROM in healthy aged baseball players aged $8-28$, Levine et $\mathrm{al}^{41}$ found ER, IR and TROM of D arm to peak in quantity in the 13-14 year group, who were considered to be at a point of maximal growth during skeletal immaturity, versus both the 8-12 and 15-28 age groups. With such ROM measures consistently changing as a youth baseball player matures, the influence of bony and/or soft-tissue structures on shoulder ROM is important to consider.

Multiple studies considering the effect of humeral retroversion on shoulder rotational motion in groups of baseball players of varying skeletal maturity have been conducted, which demonstrate the presence of bony adaptations that account for changes in GIRD, external rotation gain, and TROM. ${ }^{10,28,31,36,37,48}$ In skeletally immature baseball play- 
ers, Hibberd et $\mathrm{al}^{31}$ found both GIRD and humeral retroversion to increase with age and concluded humeral retroversion to be a primary source of age-related increases in GIRD. Similar findings in studies of healthy college, 36,37 and professional baseball players, ${ }^{10,28}$ have led to general agreement on bony morphology as the primary influencer of side-to-side shifts in rotational shoulder motion.

This study found no significant differences in isometric ER strength with the shoulder positioned in both neutral and 90 degrees of abduction in the D versus ND throwing arms. Conversely, IR strength in the D arm was $13 \%$ higher in neutral and $9 \%$ higher in 90 degrees abduction compared with the ND arm $(p=.000,0.001)$. In a study of risk factors for elbow injury in baseball players aged 9-12, Harada et $\mathrm{al}^{49}$ found no significant differences in ER or IR strength (neutral and 90 deg. abduction) between D and ND arms but did find ER strength exceeding $80 \mathrm{~N}$ and IR strength exceeding $100 \mathrm{~N}$ to be risk factors for elbow pain (Odds ratios: 4.11, 2.04 respectively). In a comparison of baseball players (average age 15.7) with and without history of shoulder or elbow pain in the previous season, Trakis et $\mathrm{al}^{50}$ found the group with injury history showed increased IR strength of D arm versus ND arm (19\% vs. $6 \%, p<.05)$. In a population of 11-12 year old baseball players with throwing-related pain, there were no side to side differences in strength or ROM. ${ }^{51}$ To the authors knowledge, there is little published norma- tive data regarding rotator cuff muscle strength in healthy youth baseball players aged 5-12 and the findings of this study can serve to inform clinicians of descriptive values for such a population.

ER/IR strength ratios have been used as a means for studying rotator cuff muscle balance in the comparison of strength characteristics within throwers D and ND extremities, and between D extremities in groups of throwers. ${ }^{17,42,52-60}$ In the present study of healthy male youth baseball players aged 5-12, D and ND arms were found to have different ER/IR ratios at neutral and 90 degrees of abduction ( 0.76 vs. 0.82 and 0.75 vs. 0.83 in neutral, 90 abd for D and ND arms respectively). These findings align with the ratios published by Ellenbecker et $\mathrm{al}^{56}$ in a study of healthy elite junior tennis players aged 12-17. Ellenbecker et al found isokinetic ER/IR strength ratios at 90 degrees abduction of 0.69 for the $\mathrm{D}$ arm and 0.82 for the ND arm. ${ }^{56}$ With no significant differences found between ER strength in D versus ND arms in the present or Ellenbecker et al ${ }^{56}$ studies, dissimilar ER/IR strength ratios in the extremities is explained by relative increase of IR strength in the D compared to ND extremity. Byram et $\mathrm{l}^{53}$ reports the majority of studies of throwers D arm ER/IR strength ratios to range from $0.60-0.80$, although research on professional baseball pitchers reveal higher ratios ranging from $0.83-1.19 .17,52,58-60$ 
Table 4: Reported Shoulder Rotational ROM Characteristics in Healthy Baseball Players

\begin{tabular}{|c|c|c|c|c|c|c|c|c|}
\hline Author & Average Age & $\mathbf{N}$ & DER & NDER & DIR & NDIR & DTROM & NDTROM \\
\hline Brown et al. 42 & 27 & 18 Professional Baseball Pitchers & 141 & 132 & 83 & 98 & 224 & 230 \\
\hline Brown et al. ${ }^{42}$ & 27 & 23 Professional Baseball Position Players & 132 & 124 & 85 & 91 & 217 & 215 \\
\hline Chou et al. 45 & 16.2 & 24 High School Baseball Players & 138 & 119 & 49 & 66 & 186 & 185 \\
\hline Chou et al. ${ }^{45}$ & 20.3 & 24 College Baseball Players & 138 & 119 & 36 & 50 & 173 & 168 \\
\hline Crocket et al. ${ }^{10}$ & & 25 Professional Baseball Pitchers aged 18-35 & 128 & 119 & 62 & 71 & 189 & 189 \\
\hline Downar et al. ${ }^{32}$ & 20 & 27 Professional Baseball Players & 109 & 102 & 57 & 69 & 166 & 170 \\
\hline Ellenbecker et al. $^{3}$ & 22.6 & 46 Professional Baseball Players & 103 & 95 & 42 & 52 & 146 & 147 \\
\hline Hibberd et al. ${ }^{31}$ & 8.3 & 52 Youth Baseball Players aged 6-10 & 122 & 120 & 52 & 55 & 174 & 175 \\
\hline Hibberd et al. ${ }^{31}$ & 11.9 & 52 Junior High Baseball Players aged 11-13 & 126 & 123 & 54 & 57 & 180 & 179 \\
\hline Hibberd et al. ${ }^{31}$ & 14.6 & 70 Junior Varsity Baseball Players aged 14-16 & 123 & 116 & 46 & 55 & 169 & 171 \\
\hline Hibberd et al. ${ }^{31}$ & 16.9 & 113 Varsity Baseball Players aged 16-18 & 123 & 115 & 45 & 53 & 168 & 168 \\
\hline Hurd et al. ${ }^{38}$ & 16 & 210 High School Baseball Players aged 14-18 & 130 & 120 & 60 & 75 & 190 & 195 \\
\hline Levine et al. ${ }^{41}$ & 10.3 & 100 Youth Baseball Players aged 8-12 & 96 & 94 & 33 & 37 & 129 & 131 \\
\hline Levine et al. 41 & 13.5 & 100 Youth Baseball Players aged 13-14 & 115 & 105 & 40 & 49 & 155 & 154 \\
\hline Levine et al. ${ }^{41}$ & 18.1 & 98 Baseball Players aged 15-28 & 109 & 94 & 38 & 54 & 147 & 148 \\
\hline Meister et al. ${ }^{11}$ & & 25 Youth Baseball Players age 8 & 152 & 145 & 39 & 42 & 191 & 187 \\
\hline Meister et al. ${ }^{11}$ & & 28 Youth Baseball Players age 9 & 146 & 142 & 42 & 44 & 188 & 186 \\
\hline Meister et al. ${ }^{11}$ & & 44 Youth Baseball Players age 10 & 144 & 141 & 41 & 44 & 184 & 186 \\
\hline Meister et al. ${ }^{11}$ & & 36 Youth Baseball Players age 11 & 146 & 142 & 40 & 43 & 186 & 185 \\
\hline Meister et al. ${ }^{11}$ & & 35 Youth Baseball Players age 12 & 142 & 138 & 38 & 43 & 180 & 180 \\
\hline Meister et al. ${ }^{11}$ & & 52 Youth Baseball Players age 13 & 143 & 135 & 36 & 45 & 179 & 180 \\
\hline Meister et al. ${ }^{11}$ & & 35 Youth Baseball Players age 14 & 141 & 131 & 29 & 40 & 170 & 171 \\
\hline Meister et al. ${ }^{11}$ & & 24 Youth Baseball Players age 15 & 133 & 125 & 27 & 32 & 159 & 157 \\
\hline Meister et al. ${ }^{11}$ & & 15 Youth Baseball Players age 16 & 132 & 122 & 21 & 33 & 159 & 155 \\
\hline Meister et al. ${ }^{11}$ & 12 & 294 Youth Baseball Players aged 8-16 & 143 & 137 & 36 & 42 & 179 & 178 \\
\hline Myers et al. ${ }^{47}$ & 21.2 & 11 College/Semi-Professional Baseball Players & 121 & 116 & 51 & 62 & 172 & 178 \\
\hline Oliver et al. ${ }^{40}$ & 11.3 & 26 Youth Baseball Players & 110 & & 35 & & 145 & \\
\hline Osbahr et al. ${ }^{36}$ & 19.1 & 19 College Baseball Pitchers aged 18-21 & 127 & 115 & 79 & 91 & 206 & 206 \\
\hline Oyama et al. ${ }^{39}$ & 16.5 & 791 High School Baseball Players & 117 & 113 & 43 & 51 & 161 & 165 \\
\hline
\end{tabular}




\begin{tabular}{|c|c|c|c|c|c|c|c|c|}
\hline Author & Average Age & $\mathbf{N}$ & DER & NDER & DIR & NDIR & DTROM & NDTROM \\
\hline Reagan et al. ${ }^{37}$ & 19.3 & 54 College Baseball Players aged $18-23$ & 116 & 106 & 43 & 51 & 160 & 158 \\
\hline Reuther et al. ${ }^{28}$ & 22.5 & 30 Professional Baseball Pitchers & 99 & 96 & 50 & 61 & 148 & 157 \\
\hline Sauers et al. ${ }^{33}$ & 22 & 99 Professional Baseball Players & 95 & 88 & 41 & 50 & 136 & 136 \\
\hline Shanley et al. ${ }^{5}$ & 15.6 & 103 High School Softball Players aged 13-18 & 124 & 122 & 60 & 67 & 184 & 189 \\
\hline Shanley et al. ${ }^{5}$ & 15.8 & 143 High School Baseball Players aged 13-18 & 126 & 118 & 54 & 61 & 180 & 179 \\
\hline Shanley et al. ${ }^{34}$ & 23.4 & 33 Professional Baseball Players & 127 & 121 & 46 & 50 & 172 & 171 \\
\hline Shanley et al. ${ }^{34}$ & 24.4 & 33 Professional Baseball Players & 139 & 126 & 38 & 51 & 175 & 177 \\
\hline Takeuchi et al. ${ }^{48}$ & 10.9 & 65 Youth Baseball Players & 115 & 113 & 41 & 49 & 156 & 161 \\
\hline Wilk et al. ${ }^{13}$ & & 369 Professional Baseball Pitchers & 132 & 127 & 52 & 63 & 184 & 190 \\
\hline Wilk et al. ${ }^{8}$ & 25.6 & 170 Professional Baseball Pitcher Seasons & 136 & 129 & 48 & 59 & 184 & 188 \\
\hline
\end{tabular}

Abbreviations: DER=Dominant External Rotation, NDER=Non-Dominant External Rotation, DIR=Dominant Internal Rotation, NDIR=Non-Dominant Internal Rotation, DTROM=Dominant Total Rotational Motion, NDTROM=Non-Dominant Total Rotational Motion -Range of motion (DER-NDTROM) values are all provided in degrees 
Currently, there is minimal published data to inform clinicians of normative values of bilateral shoulder external and internal rotation ROM and strength in youth baseball players 12 years of age and younger. ${ }^{11,31}$ As stated earlier, shoulder ROM among throwers takes on a consistent pattern across baseball players of all ages with a characteristic ER gain, IR loss, and TROM maintenance in the D arm of such athletes. The findings of this study on youth baseball players with a mean of nine years of age, help to strengthen understanding of the age ranges such ROM patterns can be expected to present clinically. If a youth athlete should present with throwing-related pain, routine ROM measures can help to guide intervention strategies including ROM restoration programs including stretching and manual therapies if indicated.

The use of hand-held dynamometers in the evaluation of isometric rotator cuff strength testing is clinically feasible, time efficient, and offers an objective means of tracking strength changes. For youth baseball players, clinicians may expect increased IR and equivalent ER muscle strength of the throwing arm versus non-throwing arm. These characteristics may be quantified using ER/IR ratio calculations to identify throwers falling outside of the accepted $0.60-0.80$ strength ratio. Rotator-cuff specific strengthening programs can be employed to increase ER/IR ratios and have been shown to be effective for such goals. ${ }^{54}$ Additionally, the monitoring of ER/IR ratios may guide clinicians on appropriate timing of return to throwing following throwingrelated injury. 53

The limitations of this study include a relatively small sample size of 50 participants ranging from 5-12 years of age. As a result, the authors were unable to run ROM and strength analyses of specific age groups within this broad age range of athletes up to seven years apart. Additionally, the influence of descriptive information including height, weight, years of baseball experience, and injury history on the ROM and strength measures collected is unknown. All strength and ROM measures were taken in a single trial which may increase the risk of measurement error.

\section{CONCLUSION}

The results of the current study indicate that youth baseball players with a mean age of 9.02 years (age range 5-12) demonstrated no significant difference in total rotation ROM between extremities, however had significantly greater dominant arm ER and significantly less dominant arm IR. There were no significant differences in ER isometric strength between extremities both in neutral and in 90 degrees of abduction. However, significant increases in dominant arm IR isometric strength were identified in both neutral and 90 degrees of abduction. These results are consistent with findings reported in many other studies in older, more developed and mature overhead throwing athletes, indicating sport specific ROM and strength adaptations. These data can assist clinicians who work with athletes in this population and age range to inform prevention and treatment of overuse throwing injuries.

\section{CONFLICTS OF INTEREST}

The authors certify that they have no affiliations with or financial involvement in any organization or entity with a direct financial interest in the subject matter or materials discussed in this article.

\section{ACKNOWLEDGEMENTS}

The authors would like to thank Jessica Endo, DPT, Sports Resident at Los Gatos Orthopedic Sports Therapy for her contribution with helping us bring this to publication. Without her work, effort and persistence, we would not have been able to accomplish the endeavor.

Submitted: November 05, 2019 CDT, Accepted: July 24, 2020 CDT 


\section{REFERENCES}

1. Ellenbecker TS. Shoulder internal and external rotation strength and range of motion of highly skilled junior tennis players. Isokinet Exerc Sci. 1992;2(2):65-72. https://doi.org/10.3233/IES-1992-22 $\underline{05}$.

2. Ellenbecker TS. A total arm strength isokinetic profile of highly skilled tennis players. Isokinet Exerc Sci. 1991;1(1):9-21. https://doi.org/10.3233/IES-199 1-1103.

3. Ellenbecker TS, Roetert EP, Bailie DS, Davies GJ, Brown SW. Glenohumeral joint total rotation range of motion in elite tennis players and baseball pitchers. Med Sci Sports Exerc. 2002;34(12):2052-2056. doi:10.1 $\underline{097 / 00005768-200212000-00028}$

4. Kibler WB, Chandler TJ, Livingston BP, Roetert EP. Shoulder range of motion in elite tennis players. Effect of age and years of tournament play. Am J Sports Med. 1996;24(3):279-285. doi:10.1177/0363546 59602400306

5. Shanley E, Rauh MJ, Michener LA, Ellenbecker TS, Garrison JC, Thigpen CA. Shoulder range of motion measures as risk factors for shoulder and elbow injuries in high school softball and baseball players. Am J Sports Med. 2011;39(9):1997-2006. doi:10.1177/0 $\underline{363546511408876}$

6. Reinold MM, Gill TJ, Wilk KE, Andrews JR. Current concepts in the evaluation and treatment of the shoulder in overhead throwing athletes, part 2: Injury prevention and treatment. Sports Health.

2010;2(2):101-115. doi:10.1177/1941738110362518

7. Burkhart SS, Morgan CD, Kibler BW. The disabled throwing shoulder: Spectrum of pathology Part I: Pathoanatomy and biomechanics. Arthrosc - J Arthrosc Relat Surg. 2003;19(4):404-420. doi:10.1053/i ars.2003.50128

8. Wilk KE, MacRina LC, Fleisig GS, et al. Correlation of glenohumeral internal rotation deficit and total rotational motion to shoulder injuries in professional baseball pitchers. Am J Sports Med. 2011;39(2):329-335. doi:10.1177/0363546510384223

9. Borsa PA, Wilk KE, Jacobson JA, et al. Correlation of range of motion and glenohumeral translation in professional baseball pitchers. Am J Sports Med. 2005;33(9):1392-1399. doi:10.1177/036354650427349 $\underline{0}$
10. Crockett HC, Gross LB, Wilk KE, et al. Osseous adaptation and range of motion at the glenohumeral joint in professional baseball pitchers. Am J Sports Med. 2002;30(1):20-26. doi:10.1177/03635465020300 $\underline{011701}$

11. Meister K, Day T, Horodyski M, Kaminski TW, Wasik MP, Tillman S. Rotational motion changes in the glenohumeral joint of the adolescent/Little league baseball player. Am J Sports Med. 2005;33(5):693-698. doi:10.1177/0363546504269936

12. Wilk KE, Meister K, Andrews JR. Current concepts in the rehabilitation of the overhead throwing athlete. Am J Sports Med. 2002;30(1):136-151. doi:1 $\underline{0.1177 / 03635465020300011201}$

13. Wilk KE, MacRina LC, Arrigo C. Passive range of motion characteristics in the overhead baseball pitcher and their implications for rehabilitation. Clin Orthop Relat Res. 2012;470(6):1586-1594. doi:10.100 7/s11999-012-2265-Z

14. Fleisig GS, Andrews JR, Dillman CJ, Escamilla RF. Kinetics of Baseball Pitching with Implications About Injury Mechanisms. Am J Sports Med. 1995;23(2):233-239. doi:10.1177/03635465950230021 $\underline{8}$

15. Fleisig GS, Barrentine SW, Escamilla RF, Andrews JR. Biomechanics of overhand throwing with implications for injuries. Sport Med. 1996;21(6):421-437. doi:10.2165/00007256-19962106 $\underline{0-00004}$

16. Manske R, Wilk KE, Davies GJ, Ellenbecker TS, Reinold M. Glenohumeral motion deficits: Friend or foe? Int J Sports Phys Ther. 2013;8(5):537-553.

17. Donatelli R, Ellenbecker TS, Ekedahl SR, Wilkes JS, Kocher K, Adam J. Assessment of shoulder strength in professional baseball pitchers. J Orthop Sports Phys Ther. 2000;30(9):544-551. doi:10.2519/jospt.2000.3 $\underline{0.9 .544}$

18. Dillman CJ, Fleisig GS, Andrews JR. Biomechanics of pitching with emphasis upon shoulder kinematics. J Orthop Sports Phys Ther. 1993;18(2):402-408. doi:1 $\underline{0.2519 / j o s p t .1993 .18 .2 .402}$

19. Jobe FW, Tibone JE, Perry J, Moynes D. An EMG analysis of the shoulder in throwing and pitching. A preliminary report. Am J Sports Med. 1983;11(1):3-5. d. oi: $10.1177 / 036354658301100102$ 
20. Jobe FW, Moynes DR, Tibone JE, Perry J. An EMG analysis of the shoulder in pitching. A second report. Am J Sports Med. 1984;12(3):218-220. doi:10.1177/036 354658401200310

21. Gowan ID, Jobe FW, Tibone JE, Perry J, Moynes DR. A comparative electromyographic analysis of the shoulder during pitching. Professional versus amateur pitchers. Am J Sports Med. 1987;15(6):586-590. doi:10.1177/03635465870150061 1

22. Fleisig GS, Andrews JR, Cutter GR, et al. Risk of serious injury for young baseball pitchers: A 10-year prospective study. Am J Sports Med.

2011;39(2):253-257. doi:10.1177/0363546510384224

23. Dutra T. Baseball and Softball. Pediatrics. 2012;129(3):e842-e856.

24. Matsuura T, Suzue N, Iwame T, Arisawa K, Fukuta S, Sairyo K. Epidemiology of shoulder and elbow pain in youth baseball players. Phys Sportsmed. 2016;44(2):97-100. doi:10.1080/00913847.2016.11494 $\underline{22}$

25. Takagishi K, Matsuura T, Masatomi T, et al. Shoulder and elbow pain in junior high school baseball players: Results of a nationwide survey. $J$ Orthop Sci. 2019;24(4):708-714. doi:10.1016/j.jos.201 $\underline{8.12 .018}$

26. Takagishi K, Matsuura T, Masatomi T, et al. Shoulder and elbow pain in elementary school baseball players: The results from a nation-wide survey in Japan. J Orthop Sci. 2017;22(4):682-686. do $\mathrm{i}: 10.1016 /$ i.jos.2017.03.016

27. Lyman, S, Fleisig GS. Baseball injuries. Med Sport Sci. 2005;49:9-30. https://doi.org/10.1159/000085340.

28. Reuther KE, Sheridan S, Thomas SJ.

Differentiation of bony and soft-tissue adaptations of the shoulder in professional baseball pitchers. $J$ Shoulder Elb Surg. 2018;27(8):1491-1496. doi:10.1016/ j.jse.2018.02.053

29. Riemann BL, Davies GJ, Ludwig L, Gardenhour H. Hand-held dynamometer testing of the internal and external rotator musculature based on selected positions to establish normative data and unilateral ratios. J shoulder Elb Surg. 2010;19(8):1175-1183. do $\mathrm{i}: 10.1016 / \mathrm{i} . \mathrm{j} s \mathrm{se} 2010.05 .021$

30. Bohannon RW. Intertester reliability of hand-held dynamometry: A concise summary of published research. Percept Mot Skills. 1999;88(3 Pt 1):899-902.
31. Hibberd EE, Oyama S, Myers JB. Increase in humeral retrotorsion accounts for age-related increase in glenohumeral internal rotation deficit in youth and adolescent baseball players. Am J Sports Med. 2014;42(4):851-858. doi:10.1177/036354651351 9325

32. Downar JM, Sauers EL. Clinical Measures of Shoulder Mobility in the Professional Baseball Player. J Athl Train. 2005;40(1):23-29.

33. Sauers EL, Huxel Bliven KC, Johnson MP, Falsone $S$, Walters S. Hip and glenohumeral rotational range of motion in healthy professional baseball pitchers and position players. Am J Sports Med. 2014;42(2):430-436. doi:10.1177/0363546513508537

34. Shanley E, Thigpen CA, Clark JC, et al. Changes in passive range of motion and development of glenohumeral internal rotation deficit (GIRD) in the professional pitching shoulder between spring training in two consecutive years. J Shoulder Elb Surg. 2012;21(11):1605-1612. doi:10.1016/j.jse.2011.11.035

35. Wilk KE, Macrina LC, Fleisig GS, et al. Deficits in glenohumeral passive range of motion increase risk of shoulder injury in professional baseball pitchers. Am J Sports Med. 2015;43(10):2379-2385. doi:10.1177/0363 546515594380

36. Osbahr DC, Cannon DL, Speer KP. Retroversion of the humerus in the throwing shoulder of college baseball pitchers. Am J Sports Med. 2002;30(3):347-353. doi:10.1177/03635465020300030 801

37. Reagan KM, Meister K, Horodyski MB, Werner DW, Carruthers C, Wilk K. Humeral retroversion and its relationship to glenohumeral rotation in the shoulder of college baseball players. Am J Sports Med. 2002;30(3):354-360. doi:10.1177/03635465020300030 $\underline{901}$

38. Hurd WJ, Kaplan KM, Eiattrache NS, Jobe FW, Morrey BF, Kaufman KR. A profile of glenohumeral internal and external rotation motion in the uninjured high school baseball pitcher, part I: Motion. J Athl Train. 2011;46(3):282-288. doi:10.408 5/1062-6050-46.3.282

39. Oyama S, Hibberd EE, Myers JB. Preseason screening of shoulder range of motion and humeral retrotorsion does not predict injury in high school baseball players. J Shoulder Elb Surg. 2017;26(7):1182-1189. doi:10.1016/j.jse.2017.03.038

40. Oliver GD, Weimar WH. Hip and Shoulder Range of Motion in Youth Baseball Pitchers. J strength Cond Res. 2016;30(10):2823-2827. doi:10.1519/isc.0000000 $\underline{000000796}$ 
41. Levine WN, Brandon ML, Stein BS, Gardner TR, Bigliani LU, Ahmad CS. Shoulder adaptive changes in youth baseball players. J Shoulder Elb Surg. 2006;15(5):562-566. doi:10.1016/i.jse.2005.11.007

42. Brown LP, Niehues SL, Harrah A, Yavorsky P, Hirshman HP. Upper extremity range of motion and isokinetic strength of the internal and external shoulder rotators in major league baseball players. Am J Sports Med. 1988;16(6):577-585. doi:10.1177/036 $\underline{354658801600604}$

43. Chandler TJ, Kibler WB, Uhl TL, Wooten B, Kiser A, Stone E. Flexibility comparisons of junior elite tennis players to other athletes. Am J Sports Med. 1990;18(2):134-136. doi:10.1177/03635465900180020 $\underline{4}$

44. Chinn CJ, Priest JD, Kent BE. Upper extremity range of motion, grip strength, and girth in highly skilled tennis players. Phys Ther. 1974;54(5):474-483. doi:10.1093/ptj/54.5.474

45. Chou PP-H, Chou Y-L, Wang Y-S, Wang R-T, Lin $\mathrm{H}-\mathrm{T}$. Effects of glenohumeral internal rotation deficit on baseball pitching among pitchers of different ages. J Shoulder Elb Surg. 2018;27(4):599-605. doi:10.1016/ j.jse.2017.09.001

46. Ellenbecker TS, Roetert EP, Piorkowski PA, Schulz DA. Glenohumeral joint internal and external rotation range of motion in elite junior tennis players. J Orthop Sports Phys Ther. 1996;24(6):336-341. doi:10.2519/jospt.1996.24.6.336

47. Myers JB, Laudner KG, Pasquale MR, Bradley JP, Lephart SM. Glenohumeral range of motion deficits and posterior shoulder tightness in throwers with pathologic internal impingement. Am J Sports Med. 2006;34(3):385-391. doi:10.1177/0363546505281804

48. Takeuchi S, Yoshida M, Sugimoto K, Tsuchiya A, Takenaga T, Goto $\mathrm{H}$. The differences of humeral torsion angle and the glenohumeral rotation angles between young right-handed and left-handed pitchers. J Shoulder Elb Surg. 2019;28(4):678-684. do i:10.1016/j.jse.2018.09.002

49. Harada M, Takahara M, Mura N, Sasaki J, Ito T, Ogino T. Risk factors for elbow injuries among young baseball players. J Shoulder Elb Surg.

2010;19(4):502-507. doi:10.1016/j.jse.2009.10.022

50. Trakis JE, McHugh MP, Caracciolo PA, Busciacco L, Mullaney M, Nicholas SJ. Muscle strength and range of motion in adolescent pitchers with throwingrelated pain: Implications for injury prevention. $A m \mathrm{~J}$ Sports Med. 2008;36(11):2173-2178. doi:10.1177/0363 $\underline{546508319049}$
51. Mickevičius M, Rutkauskas S, Sipavičienė S, et al. Absence of bilateral differences in child baseball players with throwing-related pain. Int J Sports Med. 2016;37(12):952-957. doi:10.1055/s-0042-106297.

52. Sirota SC, Malanga GA, Eischen JJ, Laskowski ER. An eccentric- and concentric-strength profile of shoulder external and internal rotator muscles in professional baseball pitchers. Am J Sports Med. 1997;25(1):59-64. doi:10.1177/036354659702500111

53. Byram IR, Bushnell BD, Dugger K, Charron K, Harrell FEJ, Noonan TJ. Preseason shoulder strength measurements in professional baseball pitchers: Identifying players at risk for injury. Am J Sports Med. 2010;38(7):1375-1382. doi:10.1177/036354650936040 $\underline{4}$

54. Niederbracht Y, Shim AL, Sloniger MA, Paternostro-Bayles M, Short TH. Effects of a shoulder injury prevention strength training program on eccentric external rotator muscle strength and glenohumeral joint imbalance in female overhead activity athletes. $J$ strength Cond Res. 2008;22(1):140-145. doi:10.1519/jsc.0b013e31815f56 $\underline{34}$

55. Hinton RY. Isokinetic evaluation of shoulder rotational strength in high school baseball pitchers. Am J Sports Med. 1988;16(3):274-279. doi:10.1177/036 $\underline{354658801600314}$

56. Ellenbecker T, Roetert EP. Age specific isokinetic glenohumeral internal and external rotation strength in elite junior tennis players. J Sci Med Sport. 2003;6(1):63-70. doi:10.1016/s1440-2440(03)80009-9

57. Goulet C, Rogowski I. Sling-based Exercise for External Rotator Muscles: Effects on Shoulder Profile in Young Recreational Tennis Players. J Sport Rehabil. 2018;27(1):30-36. doi:10.1123/jsr.2015-0209

58. Scoville CR, Arciero RA, Taylor DC, Stoneman PD. End range eccentric antagonist/concentric agonist strength ratios: A new perspective in shoulder strength assessment. J Orthop Sports Phys Ther. 1997;25(3):203-207. doi:10.2519/jospt.1997.25.3.203

59. Noffal GJ. Isokinetic eccentric-to-concentric strength ratios of the shoulder rotator muscles in throwers and nonthrowers. Am J Sports Med. 2003;31(4):537-541. doi:10.1177/03635465030310041 $\underline{001}$

60. Magnusson SP, Gleim GW, Nicholas JA. Shoulder weakness in professional baseball pitchers. Med Sci Sports Exerc. 1994;26(1):5-9. doi:10.1249/00005768-1 99401000-00003 